\title{
The Measurement of Personal Self-Efficacy in Preparing for a Hurricane and Its Role in Modeling the Likelihood of Evacuation
}

\author{
Alan E. Stewart \\ CHDS Department, 402 Aderhold Hall, University of Georgia, Athens 30602, GA, USA; \\ E-Mail: aeswx@uga.edu; Tel.: +1-706-542-1812; Fax: +1-706-542-4130 \\ Academic Editor: Rick Luettich
}

Received: 7 April 2015 / Accepted: 1 July 2015 / Published: 21 July 2015

\begin{abstract}
Storm surges require that coastal residents make necessary preparations and evacuate the coast prior to hurricane landfall. An important individual characteristic in preparing for tropical cyclones is hurricane personal self-efficacy. Coastal residents who believe that it is possible to prepare for and evacuate ahead of a hurricane (hurricane response possibilities) and, further, believe that they personally can prepare and evacuate (hurricane personal self-efficacy) will be better prepared for hurricanes. In this study the author used a sample of 334 people to evaluate an 8-item self-report measure, the Hurricane Personal Self-Efficacy Scale (HPSES). This measure can be used to assess beliefs that it is possible in general to prepare for a hurricane and that the respondent him or herself can make these preparations and evacuate ahead of a hurricane. A factor analysis confirmed that the items measured two characteristics: (1) beliefs that is it possible for people in general to prepare for a hurricane; and (2) beliefs that the respondent personally could prepare for a hurricane and evacuate. The author also examined the functionality of the measure within a framework that was informed by Protection Motivation Theory (PMT). Hurricane response possibility beliefs, prior experiences with hurricane evacuation and hurricane-related property damages, and a tendency for people to sense and observe the weather were all predictive of personal self-efficacy in preparing for hurricanes, $R^{2}{ }_{a d j}=0.36$. In operationalizing other constructs associated with PMT using weather-related psychological measures in a path analysis model, it was found that personal self-efficacy, fear of consequences of the severe and extreme weather, and appraisal of the threats posed by behaviors that could result in injury or death during severe weather together predicted the self-reported likelihood of evacuating, $R^{2}{ }_{\text {adj }}=0.26$.
\end{abstract}


The implications of the study for coastal engineers and planners, ways of increasing hurricane personal self-efficacy in preparing for hurricanes, and the study's limitations are discussed.

Keywords: hurricanes; storm surge; evacuation; efficacy; human behavior

\section{Introduction}

Approximately 2544 people died in the United States from 1963 to 2012 from tropical cyclones in the Atlantic Ocean [1]. Although hurricanes and tropical storms may bring a variety of severe weather (e.g., rain, wind, tornadoes) that results in property damage, injuries, or deaths, the storm surge from tropical cyclones has historically posed the most deadly hazard, accounting for $49 \%$ of the deaths from 1963 to 2012 [1]. Recent hurricanes have produced some noteworthy storm surges that rapidly affected widespread areas and caught coastal dwellers by surprise with respect to the surge depth and force of the water [2,3]. The storm surge of Hurricane Katrina in 2005 contributed to the collapse of the levee system and the ensuing fatalities from drowning when regions like the lower 9th district in New Orleans were suddenly inundated. Hurricane Katrina also produced a 24-28 foot (7.3 to $8.5 \mathrm{~m}$ ) storm surge that was 20 miles $(32.2 \mathrm{~km})$ wide, centered on St. Louis Bay, Mississippi that killed at least 180 people in that state [4]. Hurricane Ike, a large category 2 storm when it made landfall, brought a 10-15 foot (3.0 to $4.6 \mathrm{~m}$ ) storm surge to the Galveston Island and Galveston Bay area of Texas in 2008 [5]. Hurricane Sandy produced historic damages in New Jersey, New York, and Connecticut in 2012 when storm surges ranging from 3 to 9 feet ( 0.91 to $2.7 \mathrm{~m}$ ) occurred in the New York City metropolitan area and along the central and north coasts of New Jersey [6]. The implications of these recent storms are clear: Tropical cyclones that bring the potential of storm surge to an area demand that coastal residents prepare ahead of the storm and then evacuate to safer areas inland.

There is evidence that coastal residents do not possess a full understanding or awareness of the dangers that storm surges can create [1-3,7-9]. One possible reason for this is that forecasters historically have used the Saffir-Simpson Hurricane Wind Scale (SSHWS) to convey the intensity of hurricanes $[10,11]$. This use of the SSHWS along with narratives that emphasize the maximum sustained winds in a tropical cyclone may have had the effect of communicating that the most potent threats come from high winds. In recognition of the need to communicate the dangers of storm surges, the National Hurricane Center (NHC), based upon a coupled social and natural systems research approach, deployed an experimental product, $P$-Surge (probability of surge), in the 2014 hurricane season $[1,8,12]$.

The availability of additional information about the possible storm surge effects of a tropical cyclone can help coastal residents to prepare for a storm and to make decisions about whether they will evacuate the coast $[8,12,13]$. This is significant because in the face of increased societal vulnerability to hurricane impacts, hurricane preparedness and the compliance with orders to evacuate ahead of an approaching hurricane remain below desired levels [13-17]. Researchers have identified numerous variables such as the perceived strength of one's dwelling to withstand a hurricane, not having a hurricane preparedness or evacuation plan, confidence in facing subsequent hurricanes based upon prior storm experiences, concerns about caring for elderly family members or pets, and transportation problems, among others, 
that influence hurricane-related responses and that may be evaluated alongside the risks of an approaching hurricane $[14,16-30]$.

Among these influences on hurricane preparation, the variable of personal self-efficacy plays noteworthy role. The construct of self-efficacy comes from the Social Cognitive Theory (SCT) of Albert Bandura [31-33]. Bandura [33], p. 3 defined efficacy as "beliefs in one's capabilities to organize and execute the courses of action required to produce given attainments." Personal self-efficacy pertains to the degree to which a person believes that he or she can personally perform a behavior or bring about an outcome. The sense of personal self-efficacy is highly specific to the realm of activity a person is trying to learn; efficacy is not a general or global characteristic that people possess. For example, researchers discussed and examined efficacy within the contexts of: (1) engineering design [34]; (2) scientific leadership in marine ecology [35]; (3) technology adoption [36]; (4) teaching science in the K-12 grades [37]; and (5) coping with the psychological aftermath of a hurricane [38], among many others.

Beliefs about the extent to which preparatory and adaptive responses are possible in general and that an individual actually can perform these responses (personal self-efficacy) are critical in preparing for a hurricane, especially in coastal areas that may experience a storm surge. Although sheltering-in-place for a minor hurricane may place fewer demands upon coastal residents to make hurricane preparations, this is not the case for major hurricanes (i.e., category 3 or higher) or smaller storms that pose a storm surge threat. In these cases residents will likely have to evacuate to safer locations further inland in addition to securing their property prior to evacuation. It is essential for survival for people to know what to do and where to go, generally, and also to believe that they can personally perform these preparatory and evacuation behaviors. Coastal residents who know that preparatory and preventive options are possible and, further, possess the personal self-efficacy to respond appropriately will realize the benefits of innovations in storm surge modeling and the engineered infrastructure that has been designed to make coastal communities resilient to tropical cyclones [39-41].

This author's aims in this article are to: (1) Introduce a brief, 8-item measure that assesses the extent to which people believe various hurricane preparation and evacuation behaviors are possible and the extent to which they personally could perform these behaviors (personal self-efficacy); (2) Examine the psychometric properties of the measure that are important for understanding its reliability and validity for practical uses; and (3) Model the extent to which peoples' personal self-efficacy in making hurricane preparations is related to their prior experiences with the severe weather that hurricanes bring, with their prior hurricane evacuation experiences, and with their likelihood of complying with a recommended evacuation. In the sections below the author describes the development of the Hurricane Personal Self-Efficacy Scale and then discusses the theoretical framework of Protection Motivation Theory (PMT, [42,43]) in which the measure was used to model peoples' self-reported likelihood of evacuation.

\subsection{Development of the Hurricane Personal Self-Efficacy Scale (HPSES)}

Bandura stipulated in his Social Cognitive Theory that people learn many behaviors by first attending carefully to other people and the situations in which the behaviors are performed [31-33] (e.g., people preparing for a hurricane). What behaviors appear to be possible and what behaviors are performed? What stimuli seem important in guiding behaviors? Next, the theory indicates that people, encode, remember, and organize what they have been observing others do. This may take the form of remembering 
verbal instructions that they hear or read or of recalling important features of the behaviors that were performed. Beyond these memory processes, people mentally and behaviorally rehearse what was observed, remembered, and organized. Practice is important because it can help the person to omit unnecessary or wrong behaviors while reinforcing the necessary and appropriate behavioral steps. Finally, Bandura suggested that once a behavior is learned, the anticipated benefits or reinforcements for performing it serve as a motive to respond proactively [33] (e.g., evacuating because it more fully ensures safety from a storm surge).

With these features of SCT in mind, the author created 8 items (i.e., verbal statements) with the purpose of assessing the personal self-efficacy of people regarding their abilities to: Develop a safety plan for a hurricane, prepare and protect property from the hurricane, protect themselves in a hurricane, and to evacuate ahead of a hurricane. The items for Hurricane Personal Self-Efficacy Scale (HPSES) appear in Table 1. The author designed the first four items to assess the extent to which respondents believed that the hurricane preparation or evacuation responses were possible in general for people to perform (response possibilities). The knowledge that particular preparation responses are possible for people in general may come from observing or socially comparing oneself with others in a variety of ways [33]. The knowledge of possible responses, along with other influences such as personal enactment and experience with the behavior, verbal information, and physiological and emotional states, contributes to a sense of personal self-efficacy [33]. The remaining four items in the HPSES were designed to elicit respondents' perceptions of the extent to which they could personally perform the responses (personal self-efficacy). The scale instructions asked respondents to indicate their degree of agreement with each item using a 1 (Strongly Disagree) to 5 (Strongly Agree) fully-anchored rating scale.

Table 1. Items in the Hurricane Personal Self-Efficacy Scale (HPSES).

\section{Hurricane Response Possibilities}

1. It is possible for people in general to prepare and to secure their property ahead of time for a hurricane.

2. It is possible for people in general to develop a safety plan for how to deal with a hurricane.

3. It is possible for people in general to protect themselves against a hurricane.

4. It is possible for people in general to evacuate when necessary ahead of a hurricane.

\section{Hurricane Personal Self-Efficacy}

5. I feel that I can prepare and secure my property ahead of time for a hurricane.

6. I have a safety plan for how to deal with a hurricane.

7. I can protect myself against a hurricane.

8. I can evacuate when necessary ahead of a hurricane.

The author chose to develop a brief measure that tapped the global, summary perceptions of people's hurricane self-efficacy, rather than a lengthier instrument that inventoried multiple and detailed components of hurricane preparedness and evacuation behavior. The author believed that a brief measure may find more uses in research and practical settings than a longer scale. In addition, Stein et al. [26] recently established a precedent for using such brief and summative measures in assessing hurricane risk perceptions; these researchers asked a limited number of general questions about the perceptions of risks posed by a hurricane rather than a more expanded list of the different hurricane attributes that could be harmful (e.g., wind, rain, tornadoes). 


\subsection{Protection Motivation Theory: An Organizing Framework}

The author chose to evaluate the functionality of the HPSES in predicting peoples' self-reported likelihood of hurricane evacuation within a framework that was inspired by Protection Motivation Theory (PMT). Protection Motivation Theory (Figure 1) provides a valuable perspective for understanding the multiple inputs that can affect coastal residents' hurricane preparation and evacuation behavior and the role of personal self-efficacy in formulating a response to the hazard [44]. Researchers originally created PMT as a model of disease prevention and health promotion $[42,43,45]$. The author selected PMT from among other possible models (i.e., the Health Belief Model [46], Theory of Reasoned/Planned Behavior [47] Protective Action Decision Model [48,49]), because its emphasis on cognitive and emotional variables and their hypothesized inter-relationships possessed the greatest potential to extend the understanding of coastal residents' preparation and evacuation behavior. In addition to health-related behaviors, researchers have used PMT to study the behavior of people affected by flood events [50]. Two meta-analyses of studies that employed PMT have been largely supportive of the model [42,51].

The PMT model contains three major components: (1) sources of information; (2) psychological (cognitive and emotional) mediating processes; and (3) adaptation modes (see Figure 1). The author will describe PMT and illustrate its components using hurricane preparation as an example. As depicted in Figure 1, the PMT model processes proceed from left to right with respect to time. The arrows along the bottom reflect that a person may remember the results of prior experiences with model variables and that these may affect the values of variables in subsequent experiences with hurricanes. Regarding the first component, information sources reside within the person's environment and include directly-sensed inputs of the weather along with communications from various forms of media (broadcast, internet, and social media). Information may also exist within the person as personality traits or dispositions, memories of past hurricane events (intrapersonal), gathered through verbal interactions and relationships with members of one's neighborhood or community, or through nonverbal communications (e.g., observing others' behaviors in preparation for a hurricane).

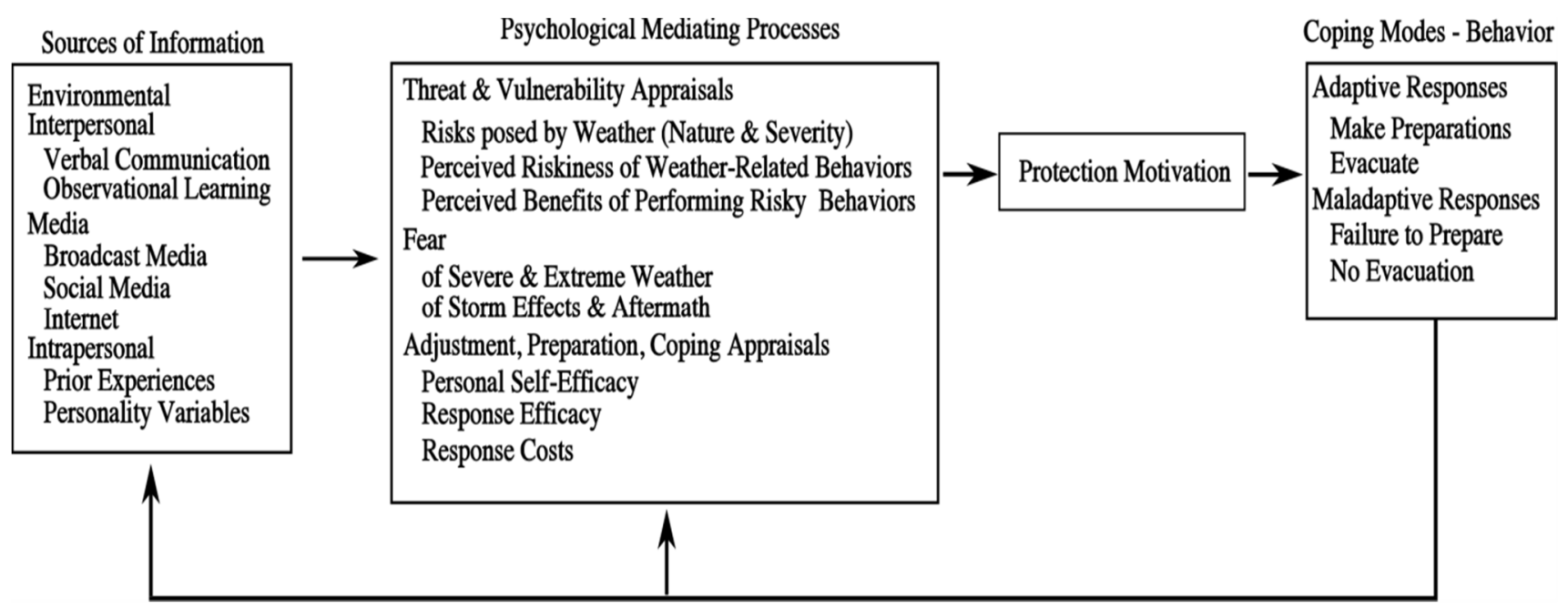

Figure 1. Protection Motivation Theory applied to the preparation and evacuation ahead of a hurricane. Adapted from Floyd, Prentice-Dunn, and Rogers [42], with permission from (C) 2000 John Wiley and Sons. 
These sources inform the second PMT component, psychological mediating processes, which involve three components that jointly contribute to an evaluation of hurricane risks and culminate in protection motivation. First, threat and vulnerability appraisals pertain to the dangerousness of a hurricane and the specific weather-related risks that it is forecasted to bring. Given these risks and the person's intended or desired behaviors, how vulnerable is the person to the hurricane's impacts? What are the costs and benefits of preparing and evacuating (or not performing these actions)? Second, fear is an important component in the PMT model because it is a powerful motivator. Given the threats and vulnerabilities that may accompany a hurricane, to what extent do these beliefs give rise to fear? In this context, fear may have to do with the hurricane-related weather phenomena (heavy rain, high winds, lightning and thunder, storm surge, etc.). Fears also may stem from the anticipated impacts that the hurricane may cause (loss of power, damage or destruction of the home, flooding, etc.).

Hurricane personal self-efficacy and response efficacy form the third part of the psychological processes in the PMT model and represent the psychologically active ingredient for mobilizing an adaptive response. Response efficacy is defined as the belief that one's responses will be effective or successful in producing a desired outcome. The likelihood of an adaptive response is increased to the extent that the person knows about appropriate adaptive behaviors to perform ahead of a hurricane (response possibilities), believes that he or she personally can perform the behaviors (personal self-efficacy), and that these behaviors will effective in protecting oneself during a hurricane (response efficacy). The perceived costs in performing these preparatory behaviors (response costs) diminish the likelihood of an adaptive response. The level of personal self-efficacy in preparing for hurricanes and other natural hazards is not only an important component of PMT, but also play a significant role in the Protective Action Decision Model [48,49].

The appraisals of threat and vulnerability, of preparation and coping, along with the level of fear that is experienced give rise to protection motivation. Protection motivation, in turn, leads to PMT's third major component: Behavioral responses. These responses may be adaptive (dwellings are secured and then evacuated ahead of the hurricane) or maladaptive (e.g., people choose to shelter in place when a storm surge is forecasted).

In summary, the PMT model provides a meaningful account of how people receive environmental information (e.g., the forecast of a hurricane landfall with an accompanying storm surge), appraise their risks (of damage by the storm, the dangers of not preparing or evacuating), experience the feelings associated with a significant natural hazard and its possible consequences (i.e., fear), and then formulate decisions and enact behavioral responses. Hurricane personal self-efficacy is significant in PMT because it relates to knowledge of what response options are possible and what the person believes she or he can actually do to prepare for the storm. The section below describes the method used to develop the HPSES, to assess its measurement properties, and, to examine its functionality within a PMT-informed framework to model the likelihood of evacuation. 


\section{Method}

\subsection{Participants}

The participants in this research were 334 university undergraduate students $(76 \%$ men) from a large university in the southeastern United States. Approximately $90 \%$ of the sample reported that they were from one of the following states: North or South Carolina, Georgia, Florida, Alabama, Mississippi, Louisiana, Tennessee, or Texas. The participants' ages ranged from 18 to 42 years, $M=21.3$ years, $S D=1.92$ years. The sample's racial identifications were as follows: Caucasian $74.6 \%$, Asian 9.4\%, African American 7.6\%, Hispanic/Latino/a 3.6\%, and Other 4.9\%. Given their residence in the southeastern United States, $15.5 \%$ of the sample reported that they or their families had sustained property damages from hurricanes previously and $13.6 \%$ of the sample indicated that they previously had evacuated their homes due to a hurricane. There were $5.8 \%$ of the participants that had both sustained hurricane-related property damage and had evacuated their homes previously.

The author relied upon a sample of university undergraduates to develop the HPSES for two reasons, the first of which pertained to the comparability of university undergraduates' responses with those of the general public with respect to weather-related attitudes, beliefs, preferences, and behaviors. In two previous investigations, the author observed that the responses of university undergraduates were very similar with those given by a representative sample of adults in the United States [52] and by those of adult residents who lived in coastal counties in the southeastern United States [17]. The second reason for relying upon an undergraduate sample stemmed from recent research reporting that 500 university students from the state of Florida lacked specific knowledge of hurricane risks and generally were unprepared for hurricanes that may affect that state [53]. Consequently, the use of an undergraduate same from the southeastern United States may be representative and instructive for developing a measure of hurricane response and self-efficacy.

The research protocol used in collecting the data for this article was reviewed and approved by the Institutional Review Board (IRB). All of the participants gave their informed consent to complete the research measures. The study participants completed the research to as part of their course requirements and received course credit for their participation.

\subsection{Measures}

The participants completed several self-report measures that were part of a larger research project whose goal was to examine the perceptions and psychological responses to weather-related risks. These measures included: (1) the HPSES (the primary focus of this article and whose items appear in Table 1); (2) the Weather Salience Questionnaire (WxSQ) [54]; (3) the Fear of Weather Scale (FOWS); (4) the Weather Risk-Taking Scale (WRTS); and (5) a demographic form assessing age, race, gender, and prior experiences with severe or extreme weather events that included experiencing property damages from hurricanes and previous experiences of hurricane evacuation. The HPSES and selected subscales of the remaining measures were used for the purposes of this article. The project measures are described more fully below. 


\subsubsection{Weather Salience Questionnaire (WxSQ)}

The WxSQ is a 29-item self-report measure that assesses seven ways in which people may find weather and weather changes to be psychologically significant or salient. The respondents read each WxSQ statement and then use a five-point fully-anchored rating scale to indicate the frequency with which they engage in a weather-related behavior $(1=$ Never to $5=$ Always $)$ or the extent of their agreement with what the item describes $(1=$ Strongly Disagree to $5=$ Strongly Agree $)$. The author has previously established the measurement characteristics of the WxSQ and its seven subscales [51,53]. A description of the subscales follows, along with the calculated value of the Cronbach's coefficient alpha $(\alpha)$ for the respondents in this sample. Cronbach's coefficient alpha ranges from 0 to 1 and provides an estimate of the internal consistency reliability of the items, that is, the extent to which they consistently assess the construct for which they were designed [55,56]. In addition, 95\% confidence intervals (CI) are provided for the alpha coefficients, based upon a Statistical Analysis System (SAS) procedure [57].

The WXSQ has yielded relatively stable scores over time, with a two-week test-retest coefficient of 0.91. People may experience the weather as psychologically significant by: (1) Seeking information about it in the media and online (9 items, $\alpha=0.75$, CI: 0.70 to 0.80 ); (2) Sensing and observing the weather directly (5 items, $\alpha=0.70$, CI: 0.65 to 0.75 ); (3) Experiencing different mood states that stem from weather or weather changes ( 6 items, $\alpha=0.80$, CI: 0.76 to 0.83 ); (4) The impact of weather effects on activities of daily life ( 3 items, $\alpha=0.45$, CI: 0.35 to 0.56 ); (5) Noticing the variability and changeability of the weather (4 items, $\alpha=0.70, \mathrm{CI}$ : 0.65 to 0.76 ); (6) Experiencing psychological attachments for various kinds of synoptic weather ( 3 items, $\alpha=0.89$, CI: 0.87 to 0.92 ); and (7) The disruption of daily routines (work or school) due to severe or extreme weather (3 items, $\alpha=0.74, \mathrm{CI}: 0.67$ to 0.80 ). Two of WxSQ items load on two subscales. The internal consistency reliability (Cronbach's $\alpha$ coefficient) of the $29 \mathrm{WxSQ}$ items was $0.81, \mathrm{CI}: 0.76$ to 0.84 .

The author used the first two WxSQ subscales (1) Seeking weather information; and (2) Sensing and observing the weather) to operationalize the information sources part of the PMT model that pertains to inputs from the natural environment.

\subsubsection{Fear of Weather Scale (FOWS)}

The author designed the remaining measures, the Fear of Weather Scale and the Weather Risk-Taking Scale, for the larger project to investigate the psychological experiences and correlates of routine, severe, and extreme weather events. The FOWS is an 87-item self-report measure whose purpose is to measure the fear of various components of severe weather (65 items) and of the effects and consequences of extreme weather events ( 22 items). For each weather component, people used a 0 (No fear) to 6 (Terror) fully-anchored rating scale to indicate their degree of fear of experiencing that type of weather. An exploratory factor analysis of the 65 severe weather items revealed 11 factors that corresponded to fears of storms and types of extreme weather: (1) Winter storms ( 8 items, $\alpha=0.95$, CI: 0.94 to 0.95 ); (2) Hurricanes (7 items, $\alpha=0.92$, CI: 0.91 to 0.94); (3) Floods (6 items, $\alpha=0.91$, CI: 0.89 to 0.92);

(4) Thunderstorms ( 7 items, $\alpha=0.91, \mathrm{CI}$ : 0.90 to 0.93 ); (5) Tornadoes (5 items, $\alpha=0.92$, CI: 0.90 to 0.93 );

(6) High winds/damaging wind storms (7 items, $\alpha=0.91$, CI: 0.89 to 0.92); (7) Heavy rainfall, (5 items, 
$\alpha=0.88$, CI: 0.85 to 0.90 ); (8) Foggy, overcast, and dark conditions (4 items, $\alpha=0.78$, CI: 0.71 to 0.81 ); (9) Fire weather/drought conditions ( 4 items, $\alpha=0.83$, CI: 0.80 to 0.86); and (10) Routine weather that may presage stormy conditions (e.g., humid, balmy, blustery conditions) ( 6 items, $\alpha=0.80$, CI: 0.73 to 0.82). The last factor pertained to non-atmospheric natural hazards and involved fears of earthquakes, tremors, and tsunamis ( 5 items, $\alpha=0.88$, CI: 0.86 to 0.90 ). One open-ended item was not factor analyzed.

The 22 items designed to assess peoples' fears of the consequences of extreme weather were associated with four factors in an exploratory factor analysis: (1) Loss of property (dwellings, belongings) and of what happens to the self and other people (loss of control over aspects of daily life) (8 items, $\alpha=0.94$, CI: 0.93 to 0.95); (2) Damage to property and belongings (7 items, $\alpha=0.94$, CI: 0.93 to 0.95); (3) Loss of utility infrastructure (e.g., power, water, natural gas, transportation systems) ( 5 items, $\alpha=0.91$, CI: 0.88 to 0.92); and (4) Danger to the physical safety of self and of others (2 items, $\alpha=0.92$, CI: 0.89 to 0.94 ). The Cronbach's alpha for the 22 items in the four subscales taken together was 0.97, CI: 0.96 to 0.97.

The scores of the items that compose each factor can be summed to create a subscale measure. The author used the FOWS Hurricane subscale and the four subscales pertaining to the fear of the consequences of extreme weather in the analyses to model hurricane evacuation likelihood. The four consequences subscales were summed to create a single composite score. The author reasoned that because hurricanes can produce such widespread and extensive damage (encompassing fear of loss and damage of property, loss of utilities, and danger to self and others), that it was acceptable to combine the subscales pertaining to fearful storm consequences.

The FOWS also contains an additional item that pertained to evacuation: If severe weather was threatening and public officials were evacuating your area, how likely is it that you would evacuate your home and seek shelter elsewhere? This question has a 6-point fully-anchored rating scale ( 1 = Not likely at all (would stay at home) to $6=$ Very likely to evacuate). The author used responses to this item as a dependent variable in modeling the likelihood of evacuation as a function of the HPSES and other project variables within the PMT framework. Specifically, the likelihood of evacuation was taken to reflect the level of protection motivation that people possessed.

\subsubsection{Weather Risk-Taking Scale (WRTS)}

The WRTS is a self-report instrument that lists 32 behaviors that people might perform in severe or extreme weather situations that have the potential for injury or death (e.g., driving over inundated roadways or bridges, remaining outside during thunderstorms or extremes of temperature, swimming or surf-boarding in storm tides, etc.). The author developed the items based upon the categories of weather events that regularly result in accidents or fatalities as reported by the National Weather Service. Various weather safety resources (e.g., National Lightning Safety Institute, the National Weather Service, American Red Cross, etc.) were consulted to identify risky weather-related behaviors as well as responses that were safe and risk-averse.

Respondents to the WRTS evaluated the 32 behaviors under three instructional sets, the first of which was the rated likelihood of their performing the behavior. The respondents used a seven-point fully-anchored rating scale $(1=$ Extremely Unlikely to $7=$ Extremely Likely) to evaluate each behavior. The second instructional set asked the respondents to evaluate the degree of riskiness associated with each behavior using a seven-point fully-anchored rating scale $(1=$ Not at all Risky to $7=$ Extremely Risky). 
The third instructional set asked the respondents to consider the potential benefits of performing each of the 32 behaviors. Again, a seven-point fully-anchored rating scale was used ( $1=$ No Benefits at All to 7 $=$ Great Benefits). The responses to each of the 32 items for the three instructional sets are summed to create scores that summarize the respondents' overall degree of perceived riskiness of the behaviors, the likelihood of performing them, and the potential benefits of performing them.

The three WRTS subscales possessed good internal consistency: Rated riskiness of the weather-related behaviors ( $\alpha=0.87$, CI: 0.85 to 0.89 ), perceived benefits of performing the behaviors ( $\alpha=0.89$, CI: 0.87 to 0.92 ), likelihood of performing the behavior s ( $\alpha=0.84, \mathrm{CI}: 0.81$ to 0.86$)$. PMT specifies that the appraisal of threat comes from differencing the intrinsic and extrinsic rewards of a potentially maladaptive response from the severity and vulnerability posed by the response [42]. Consequently, the author operationalized threat appraisal for the purposes of this study by subtracting the perceived benefits of performing the behaviors from their rated degree of riskiness for each respondent. The order of the subtraction was chosen so that the resulting numbers would be positive, which in this study conveyed a greater degree of perceived risk (or appraised threat) compared to the benefits of performing the risky behaviors. Because the WRTS subscale assessing the likelihood of performing the behaviors was highly correlated with the Risk-Benefits difference score $(r=0.89, p<0.0001)$ and because the difference score appeared to capture more fully the threat appraisal construct from PMT, the author chose not to use the WRTS likelihood subscale in the modeling analyses of this project.

\subsection{Procedure}

The participants completed the measures via networked computers in groups of 10-15 in a supervised and controlled laboratory setting. The order in which the measures were administered was varied throughout the data collection to avoid artifactual responses based upon the order in which the measures were completed. The project measures typically required 45 to $60 \mathrm{~min}$ of time for completion.

\subsection{Data Analysis}

The author used the Statistical Analysis System (SAS [58]) to calculate the descriptive statistics, and the Cronbach $(\alpha)$ coefficients. The author also used the SAS procedure known as the Covariance Analysis of Linear Structural Equations (CALIS) to assess the measurement model of the HPSES (i.e., to examine the degree to which the eight items measured hurricane response possibilities and hurricane personal self-efficacy) and to examine the contribution of the participants' demographic data, HPSES, FOWS, and WRTS to the likelihood of evacuation. Because the HPSES used an ordinal (rather than continuous) level of measurement, the relationships among the items were assessed with polychoric correlation coefficients. As recommended by several methodologists, this polychoric correlation matrix served as input to the CALIS procedure for evaluating the HPSES measurement model $[59,60]$. The author fit the both the HPSES measurement model and the path model of the likelihood of evacuation using weighted least squares estimation because some of the predictor variables deviated slightly from the standard normal distribution. In addition, because of missing data for three respondents, the sample size for the path analysis was 331 people. 


\section{Results}

\subsection{Properties of the Hurricane Personal Self-Efficacy Measure}

The descriptive statistics for the eight HPSES items appear in Table 2. The mean values for each item revealed a response tendency that ranged from uncertain (numerical value of 3 ) to agree (4) on the five-point rating scale. This result also was evident in the generally small and negative values of the skewness for each item. The second HPSES item, It is possible for people in general to develop a safety plan for how to deal with a hurricane, had higher values for skewness and kurtosis given that many people generally indicated that they agreed with the item.

Table 2. Descriptive statistics and item correlations of the HPSES items.

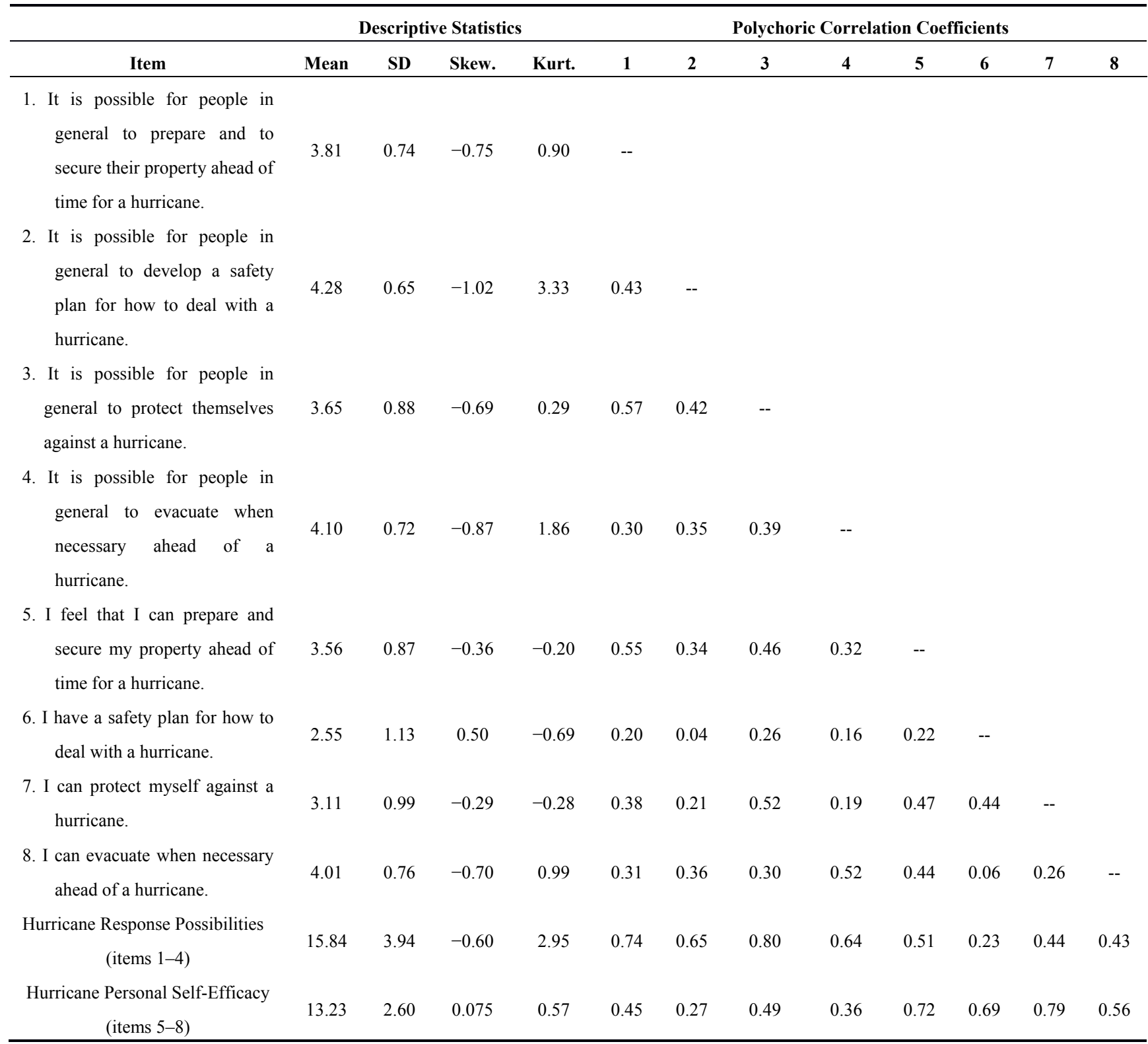

Note: The respondents used a 5-point rating scale to evaluate each item: $1=$ Strongly Disagree, 2 = Disagree, $3=$ Uncertain, $4=$ Agree, $5=$ Strongly Agree. Note that all polychoric correlations differed significantly from a value of zero with the exception of item \#2 with item \#6 and item \#6 with item \#8. 
Table 2 also shows the matrix of polychoric correlations among the HPSES items. The correlations ranged from 0.06 (items 6 and 8) to 0.57 (items 1 and 3). Item 6, I have a safety plan for how to deal with a hurricane, generally exhibited correlations that were of lower magnitude than the inter-correlations of the other items. This result may have occurred because this item assesses a self-reported behavior and because the sample of university undergraduates were living at the time of their research participation at a location that was far inland and that did not necessitate the creation of a hurricane safety plan.

The Covariance Analysis of Linear Structural Equations (i.e., the SAS CALIS procedure) was used next to evaluate the extent to which the four HPSES items (\#1 to \#4) were related to the latent variable (factor) of hurricane response possibilities and the extent to which items (\#5 to \#8) were related to the latent variable of hurricane personal self-efficacy. It was expected that because all of the HPSES items inquired about capabilities to prepare, to evacuate and to remain safe ahead of a hurricane, but differed in focus (i.e., people in general for items \#1 to \#4 and for the self in items \#5-\#8), that the two latent variables would be correlated with each other.

This HPSES measurement model demonstrated a good fit to the data when interpreting the statistics used to assess model performance [61]. The residuals between the observed correlations and those predicted by the measurement model were generally small as given by the standardized root mean residual $($ SRMR $=0.04)$. Similarly, the root mean square error of approximation (RMSEA), another absolute indicator of model fit, was acceptable at 0.06 ; the $90 \%$ confidence interval for the RMSEA was 0.03 to 0.09 . The probability of close fit index ( $p$-close) was 0.06 , a value that is associated with a good degree of fit between the model and the data. The Bentler Comparative Fit Index was 0.96 and the Bentler-Bonett Non-normed Index was 0.91 . These latter fit indices range from 0 to 1 , with higher values indicating a greater degree of fit between the measurement model and the data. In addition, the present model with two subscales exhibited significantly better fit than a model possessing a single, general scale, $X^{2}(\mathrm{df}=2)=19.02, p<0.0001$.

Table 3 shows the correlations of each item with the latent variables corresponding to hurricane response possibilities and to hurricane personal self-efficacy; all of the correlations were statistically significant. The two latent variables (hereafter referred to as subscales) were significantly correlated, as would be expected, $r=0.52, p<0.0001$.

The Cronbach's alpha for the eight item HPSES scale was $0.80, \mathrm{CI}: 0.71$ to 0.82 . The alpha coefficients were somewhat lower for the subscales because of the smaller number of items, which can attenuate the coefficient magnitude. For hurricane response possibility, $\alpha=0.67, \mathrm{CI}: 0.58$ to 0.76 and for personal self-efficacy, $\alpha=0.63$, CI: 0.55 to 0.70 .

The first four HPSES items can be summed to obtain an indication of the extent to which the respondent believed that making hurricane preparations, evacuating, and remaining safe were possible responses for people in general. Similarly, the sum of the last four items provides an indication of the respondent's sense of personal self-efficacy in preparing or evacuating before the hurricane and remaining safe. Table 2 provides the descriptive statistics for the response possibility and the personal self-efficacy subscales. The mean value of the response possibility subscale, $15.84(S D=2.14)$, corresponded qualitatively with Agree with respect to knowledge of hurricane preparation and evacuation response options for people in general. The mean value for the personal self-efficacy subscale, 13.23 $(S D=2.59)$, was somewhat lower than for response possibility and corresponded qualitatively with 
Uncertain to Agree. The mean scores on the HPSES did not differ to a statistically significant extent with respect to gender or the participants' racial identification.

Table 3. Correlations of HPSES Items with their Respective Subscales.

\begin{tabular}{|c|c|c|}
\hline Item & $\begin{array}{c}\text { Correlation } \\
\text { With Subscale }\end{array}$ & $\begin{array}{l}\text { Standard } \\
\text { Error }\end{array}$ \\
\hline \multicolumn{3}{|l|}{ Hurricane Response Possibilities } \\
\hline $\begin{array}{l}\text { 1. It is possible for people in general to prepare and to secure their } \\
\text { property ahead of time for a hurricane. }\end{array}$ & 0.71 & 0.04 \\
\hline $\begin{array}{l}\text { 2. It is possible for people in general to develop a safety plan for } \\
\text { how to deal with a hurricane. }\end{array}$ & 0.46 & 0.05 \\
\hline $\begin{array}{l}\text { 3. It is possible for people in general to protect themselves against a } \\
\text { hurricane. }\end{array}$ & 0.72 & 0.04 \\
\hline $\begin{array}{l}\text { 4. It is possible for people in general to evacuate when necessary } \\
\text { ahead of a hurricane. }\end{array}$ & 0.41 & 0.05 \\
\hline \multicolumn{3}{|l|}{ Hurricane Personal Self-Efficacy } \\
\hline $\begin{array}{l}\text { 5. I feel that I can prepare and secure my property ahead of time for } \\
\text { a hurricane. }\end{array}$ & 0.74 & 0.04 \\
\hline 6. I have a safety plan for how to deal with a hurricane. & 0.30 & 0.06 \\
\hline 7. I can protect myself against a hurricane. & 0.61 & 0.04 \\
\hline 8. I can evacuate when necessary ahead of a hurricane. & 0.50 & 0.05 \\
\hline
\end{tabular}

Note: The correlations shown are standardized estimates of the relationship of the item with the subscale. Items \#1 to \#4 are correlated with the latent variable representing the Hurricane Response Possibilities subscale. Items $\# 5$ to $\# 8$ are correlated with the latent variable representing the Hurricane Personal Self-Efficacy Subscale. All correlations were statistically significant, $p<0.0001$.

\subsection{Predictors of Hurricane Personal Self-Efficacy}

Social Cognitive Theory and Protection Motivation Theory both convey predictions about what may influence the degree of personal self-efficacy $[32,33,42]$. The knowledge or awareness that particular responses are possible for people in general presages a sense of personal self-efficacy. A person must learn and know that a particular response or set of responses is possible before he or she learns them personally [31-33]. From the perspective of SCT, people develop such awareness of the possibility of responses generally by observing others in person or via various media. Such observations provide a vicarious source of information about both the behaviors and the possible range of consequences that others might experience. These observations give a person a sense of what is possible for others in general to do or to accomplish. This also can contribute to a sense of personal self-efficacy beliefs as the person contemplates making the same responses him/herself [32,33]. Similarly, SCT and PMT each predict that people learn from their experiences. Such enacted experiences, according to Bandura, can also contribute to personal self-efficacy beliefs, especially when people believe that their response to the experience was effective.

With this theoretical background in mind, it was expected that the variable of hurricane response possibility would predict the level of personal self-efficacy that people reported. It was also expected that prior experiences with hurricane evacuation or with damages that hurricanes produced would be 
predict personal self-efficacy. PMT also predicts that information people obtain from various sources and personal experiences affect personal self-efficacy along with the assessment of risk and the possible ways of responding to the risk that are part of the PMT psychological mediating processes $[42,43]$.

Table 4. Descriptive Statistics and Pearson Correlation Coefficients ${ }^{\top}$ for Variables Considered for the Structural Model of Hurricane Personal Self-Efficacy and its Contribution of Evacuation Likelihood $(n=331)$.

\begin{tabular}{|c|c|c|c|c|c|c|c|c|c|c|}
\hline Variable & 1 & 2 & 3 & 4 & 5 & 6 & 7 & 8 & 9 & 10 \\
\hline $\begin{array}{l}\text { 1. Seeking Weather Information } \\
\text { (WxSQ Subscale) }\end{array}$ & -- & & & & & & & & & \\
\hline $\begin{array}{l}\text { 2. Sensing and Observing Weather } \\
\text { (WxSQ Subscale) }\end{array}$ & $0.44 *$ & -- & & & & & & & & \\
\hline $\begin{array}{l}\text { 3. Previously evacuated due to a } \\
\text { hurricane (yes/no) }\end{array}$ & $0.13 *$ & 0.02 & -- & & & & & & & \\
\hline $\begin{array}{l}\text { 4. Self or family sustained } \\
\text { hurricane damage previously } \\
\text { (yes/no) }\end{array}$ & 0.04 & 0.03 & $0.29 *$ & -- & & & & & & \\
\hline $\begin{array}{l}\text { 5. Hurricane Response Possibility } \\
\text { (Subscale) }\end{array}$ & 0.08 & $0.15 *$ & 0.10 & 0.09 & -- & & & & & \\
\hline $\begin{array}{l}\text { 6. Hurricane Personal } \\
\text { Self-Efficacy (Subscale) }\end{array}$ & $0.12 *$ & $0.16 *$ & $0.21 *$ & $0.21 *$ & $0.56 *$ & -- & & & & \\
\hline $\begin{array}{l}\text { 7. Weather Risk-Taking Difference } \\
\text { Score (Rated Riskiness of } \\
\text { Behavior-Perceived Benefit of } \\
\text { Performing Behavior) }\end{array}$ & $0.17 *$ & 0.04 & 0.05 & 0.01 & $0.23 *$ & 0.07 & -- & & & \\
\hline $\begin{array}{l}\text { 8. Fear of Severe/Extreme Weather } \\
\text { Effects (FOWS Subscale) }\end{array}$ & $0.15 *$ & 0.03 & 0.03 & -0.01 & 0.02 & -0.06 & $0.28 *$ & -- & & \\
\hline $\begin{array}{l}\text { 9. Fear of Hurricane-Related } \\
\text { Weather (FOWS Subscale) }\end{array}$ & 0.09 & -0.04 & -0.05 & -0.02 & -0.04 & -0.07 & $0.30 *$ & $0.55 *$ & -- & \\
\hline $\begin{array}{l}\text { 10. Self-Reported Likelihood of } \\
\text { Complying with Recommended }\end{array}$ & $0.13 *$ & 0.02 & 0.02 & 0.04 & 0.10 & $0.14 *$ & $0.38^{*}$ & $0.36 *$ & $0.28 *$ & -- \\
\hline Evacuation & & & & & & & & & & \\
\hline Mean & 31.21 & 17.80 & 0.14 & 0.16 & 15.83 & 13.25 & 107.21 & 100.63 & 25.26 & 4.69 \\
\hline Std. Deviation & 5.48 & 3.11 & 0.34 & 0.36 & 2.14 & 2.59 & 34.21 & 24.39 & 7.76 & 1.16 \\
\hline
\end{tabular}

Note: * Statistical significance $(p)<0.01 .{ }^{\mp}$ The correlations reported here are the bivariate, zero-order Pearson coefficients. The numerical values may differ slightly from those reported in Figure 2, which were calculated in fitting the full path model to the variables.

The author used path analysis to model the contributions of the information subscale and the sensing and observing subscale of the WxSQ, indicators of past hurricane damage or evacuation experiences, and the HPSES response possibility subscale to hurricane personal self-efficacy. This analysis was performed as part of a larger path analysis to model the contributions of hurricane personal self-efficacy, fear, and risk appraisals to self-reported likelihood of evacuating. The fit statistics for the full path analysis will be reported in the next section. 
The descriptive statistics and zero-order Pearson correlation coefficients for the variables considered for the path analysis appear in Table 4. The standardized values of the path coefficients appear in Figure 2 and were all statistically significant $(p<0.005)$. Hurricane response possibility was the strongest predictor of hurricane personal self-efficacy. Prior experiences with hurricane damages and with evacuating before a hurricane each made comparable and smaller contributions to levels of hurricane personal self-efficacy; people exhibited higher hurricane personal self-efficacy if they had experienced hurricane damages previously or if they had prior evacuation experience. Sensing and observing the weather directly, which is an aspect of weather salience, also made a small but statistically significant contribution to the path model. The general disposition of watching the weather and observing its changes enhanced the sense of personal self-efficacy in preparing for a hurricane.

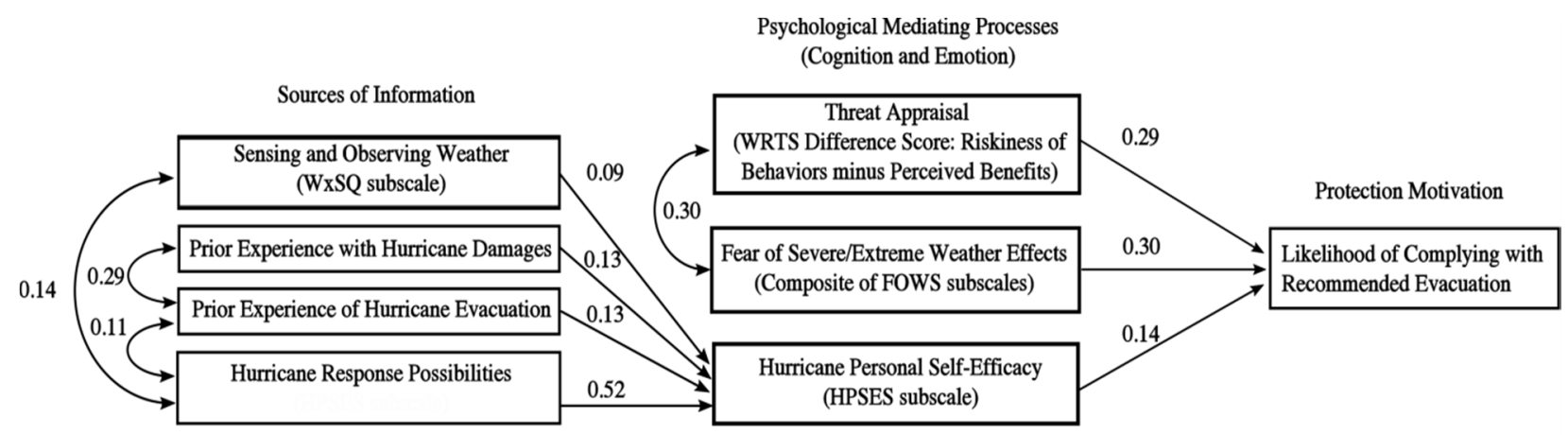

Figure 2. Path model operationalizing selected variables of Protection Motivation Theory to predict likelihood of evacuation. All path coefficients shown differed significantly from zero.

Finally, the seeking weather information subscale of the WxSQ also exhibited a small correlation with hurricane personal self-efficacy. When the seeking weather information subscale was entered into the path model however, its relationship to the other variables decreased from the values shown in the initial correlation matrix (Table 4) and its path coefficient was not statistically significant. It appeared that the WxSQ sensing and observing subscale encompassed the aspects of information, knowledge or awareness that related to the other variables in the model. In addition, the sensing and observing scale demonstrated a greater degree of relationship with hurricane personal self-efficacy than did the seeking weather information subscale. For these reasons, the seeking weather information variable subsequently was removed from the path model. The adjusted $R^{2}$ value for this part of the path analysis was 0.36 .

\subsection{Hurricane Personal Self-Efficacy and the Likelihood of Evacuation}

The PMT provides a framework for understanding how environmental inputs and the ensuing cognitive mediating processes affect the decisions people make to prepare or evacuate ahead of a hurricane (see Figures 1 and 2). In this section, the author expanded upon the path model of hurricane personal self-efficacy to assess its role in an enlarged model of the likelihood of evacuation. The PMT model brings together thinking and beliefs (cognitive processes) and emotional (or affective processes) in describing the psychological mediating processes that contribute to protection motivation. PMT specifies three components of psychological mediating processes: (1) threat appraisals posed by the phenomena under consideration and the potential maladaptive ways of responding to it; (2) fear; and 
(3) coping appraisals of performing adaptive responses. In this analysis, threat appraisals were operationalized by the WRTS difference score (i.e., rated riskiness-perceived benefits) of performing various behaviors during severe or extreme weather that could result in injury or death, as described above. The author operationalized fear via the FOWS Hurricane subscale and through the composite score encompassing various aspects of fear about the consequences of severe weather. Coping by performing an adaptive response was operationalized through the single variable of hurricane personal self-efficacy (i.e., beliefs that one could personally prepare for, evacuate, and remain safe during a hurricane).

Importantly, the present study did not attempt to operationalize or assess two other aspects that were part of the PMT model, namely the response efficacy and the response costs. Briefly, response efficacy pertains to the beliefs that a person has about the adequacy, effectiveness, or success of his/her responses. There were two reasons for not including response efficacy in this project, the first of which involved the scope of the author's work in designing the HPSES to assess only hurricane response possibilities and personal self-efficacy. Second, and relatedly, because only a portion of people in this study had reported a prior hurricane evacuation, gathering data about the efficacy of this response would not have been possible for those people who had not evacuated previously. Response costs pertain to the costs incurred to make the adaptive response in terms of things such as time, money, effort [42]. Again, because not everyone in the study had prior evacuation of hurricane experience, this variable was not operationalized.

The author used path analysis to evaluate the contributions of different model variables to the likelihood of complying with a recommended evacuation. The model is depicted in Figure 2, with information and personal disposition variables at the left, cognitive and emotional variables (psychological mediating processes) in the center, and the dependent variable, likelihood of evacuation, appearing on the right-hand side. All of the path coefficients depicted in Figure 2 were statistically significant. Some of the predictor variables also evidenced statistically significant zero-order inter-correlations and these, along with descriptive statistics, appear in Table 4.

Overall, the model fit the data well according to commonly-used indices. The chi-square test of model fit was not statistically significant, $X^{2}(\mathrm{df}=6)=7.46, p=0.28$. This non-significant chi-square statistic suggested that there were no noteworthy discrepancies between the model and the data. The standardized root mean square residual was 0.02 , indicating that the discrepancies between the model and the data were small in magnitude. Similarly, the root mean square error of approximation (RMSEA) was 0.03, indicating a good degree of model fit. The adjusted goodness of fit index was 0.95 and the Bentler-Bonett Non-normed fit index was 0.96 . These indices of model fit (with values closer to 1.0 indicating better fit) suggested that the path model conformed to the data quite well. The adjusted $R^{2}$ for the full model was 0.26 .

The prior experiences of hurricane damages or evacuation along with a disposition to sense and observe the weather exerted their influences on the likelihood of evacuating only through hurricane personal self-efficacy. In addition to its larger contribution to personal self-efficacy, hurricane response possibility exhibited a positive relationship with the threat appraisal of performing risky weather behaviors. That is, as the respondents' beliefs in the possibility of preparing for and evacuating ahead of a hurricane increased, so did the appraisals of threat posed by performing risky behaviors (i.e., the difference between perceived riskiness of the behaviors and the potential benefits of performing them). Personal self-efficacy was positively related to the likelihood of evacuating one's home when it was recommended; the value of the standardized path coefficient was 0.14 and was approximately one-half 
the magnitudes the paths of threat appraisal and of fear. The overall contribution of the variability in self-efficacy to the likelihood of evacuating was modest when considered in the context of the variability that the model accounted for in the reported likelihood to evacuate. That is, in substituting the mean values of the other predictor variables in the model, increasing hurricane self-efficacy scores from a minimum value of four (i.e., each of four HPSES items receive a rating of one) to a maximum possible value of 20 (four items each receive a rating of five), the likelihood of evacuation increased by $14.0 \%$.

The authors of the PMT indicated that the threat appraisal is related to the degree of fear that people experience [41]. This relationship was observed in the results of this project. Statistically significant correlations of comparable magnitudes existed between threat appraisal and fears of hurricane-related weather $(r=0.30)$ and fear of severe/extreme weather effects $(r=0.28$, see Table 4$)$. This result suggested that changes in threat appraisal were positively associated with changes (increases) in both fears of hurricane-related weather (e.g., winds and storm surges) and of the effects of such severe weather (i.e., property damages, losses). Fears of hurricane-related weather and fear of severe/extreme weather effects were moderately correlated $(r=0.55)$. Although both fear variables were related positively to the likelihood of evacuation, the fear of severelextreme weather effects exhibited a higher correlation (by approximately 0.10). In addition, when both fear variables were included in the path model, the contributions of the fears of hurricane-related weather to the likelihood of evacuation and to threat appraisals decreased in magnitude (from the initial correlation matrix in Table 4) and the path coefficients were no longer statistically significant. For this reason, the fears of hurricane related weather was removed from the model depicted in Figure 2. The WRTS difference score (threat appraisal, $r=0.29)$ and the fear of severe/extreme weather effects $(r=0.30)$ made comparable contributions to the prediction of the likelihood of evacuation.

\section{Discussion and Conclusions}

The data and analyses in this article were useful in the evaluation of a brief measure of hurricane response possibilities and personal self-efficacy. The author designed the HPSES to evaluate two aspects of hurricane preparedness: (1) Do people know that it is possible in general to develop a safety plan, to prepare property, to evacuate, and remain safe during a hurricane? and (2) Do respondents personally believe that they can develop their safety plans for a hurricane, prepare their property, evacuate, and remain safe? The responses of 334 people to the measure revealed that it possessed acceptable internal reliability. The first four HPSES items related to hurricane response possibilities. The remaining four items assessed hurricane personal self-efficacy. The descriptive statistics for each HPSES subscale indicated that individual respondents varied in the degree to which they believed it was possible in general for people to prepare for a hurricane and in the extent to which they personally believed that they could prepare and evacuate ahead of a hurricane.

From a weather safety perspective, personal self-efficacy in hurricane preparedness is primary because it conveys a sense of confidence-to-act. A person with a higher level of hurricane personal self-efficacy feels enabled to prepare him- or herself and, perhaps, to assist others in with their preparations. The knowledge of response possibilities (i.e., knowing that response options exist generally) also is important because it precedes, both temporally and logically, the development of the specific responses that a person can make before a hurricane. This relationship was apparent in the prediction of personal 
self-efficacy by response possibilities. Knowing that particular behavioral responses are possible through observing others in person, via the broadcast media, or through other modes of information contributes to personal self-efficacy beliefs [31-33]. Similarly, the contribution of the sensing and observing subscale of the WxSQ to hurricane response possibilities and to personal self-efficacy also was an expected result. The mindful observation of the weather, along with information from other sources like broadcast and social media, can cue people that preparatory responses and evacuation may need to occur soon $[62,63]$.

Because people generally learn from past experiences and the behaviors that they performed, it also was an expected result that the participants who had reported sustaining prior property damages from a hurricane, and thus who may have learned how to respond differently to subsequent hurricane threats, evidenced greater hurricane personal self-efficacy. Similarly, prior experiences with hurricane evacuation provide an important context for responding to subsequent hurricane threats. Once people experience the process of an initial evacuation, the learning which is accomplished at this time is available for use in future evacuation scenarios, especially if the person evaluated his or her behavior as effective or successful. This relationship was supported by the finding that prior hurricane evacuation experience positively predicted personal hurricane self-efficacy.

This project also evaluated the performance of the HPSES within a framework that was significantly informed by Protection Motivation Theory. As PMT would predict, information sources (prior experiences and environmental information) contributed to hurricane personal self-efficacy. In turn, personal self-efficacy, as it underlies making adaptive responses and coping in preparing for the storm, positively correlated with the likelihood of complying with an evacuation. The hurricane response possibilities subscale did not predict directly the likelihood of evacuating; instead, its influences were exerted through personal self-efficacy. This is an important result because it suggests that merely believing that preparation or evacuation is possible for people in general does not contribute directly to the likelihood of evacuation. General knowledge of response options was related positively to the threat appraisal as it was operationalized here as the difference between the riskiness of particular severe/extreme weather-related behaviors and the potential benefits of performing those high-risk behaviors. Thus general knowledge (i.e., hurricane response possibility) does play an important role that is distinct from personal self-efficacy.

Two additional results of this study also were consistent with what one would expect within the PMT framework. First, the positive correlation of threat appraisal with the likelihood of evacuation suggests a greater degree of motivation to protect oneself by evacuating as the perceived threats increase. Fear of the effects of severe and extreme weather exhibited a comparable degree of relationship with the likelihood of evacuation. PMT specifies that threat appraisal and fear would be related with each other and the results supported this aspect of PMT. Fear plays a noteworthy part in PMT and this theory is unique among other models in incorporating emotional experiences as these relate to protective actions. An important caveat to remember is that although the present study used a PMT-inspired framework for modeling the contributions of hurricane personal self-efficacy to the likelihood of evacuation, two constructs that are central to PMT, response efficacy and response costs were not assessed in this project. Thus, the present project does not constitute an evaluation of the PMT model, although it does illustrate its range of applicability and its usefulness in studies like this.

The establishment of the HPSES measurement properties and of its functionality in a broader PMT-inspired model of hurricane evacuation reveals the potential usefulness of the measure for research 
and applied purposes. In this regard, the present study has established HPSES measurement characteristics and illustrated the HPSES proof-of-concept in modeling the likelihood of hurricane evacuation. The measure's brevity makes it relatively easy to include along with other measures or to embed within a survey when exploring hurricane preparedness or evacuation. The brevity and straight-forward nature of the HPSES items also mean that local agencies (e.g., county emergency managers, coastal engineers or planners) could use the measure to assess the levels of personal readiness prior to the hurricane season.

The results of this research and potential prospective uses of the HPSES raise the important question of how to increase the level of hurricane response possibilities and personal self-efficacy so that people are better prepared for future storms. Although prior experience with hurricane damage and evacuation were associated with higher levels of personal self-efficacy, is there another route by which personal self-efficacy could be enhanced without actually having to experience a hurricane? Other researchers have raised similar questions about the ways that the experience of severe or extreme weather can make some people more cautious and proactive when anticipating future weather events [16,54,64].

Because hurricane self-efficacy pertains to beliefs in one's abilities to perform a behavior, efforts to increase efficacy should be at least two-tiered. First, communicating information related to hurricane safety, to evacuation routes, and the locations of inland shelters may enhance a person's knowledge of hurricane response possibilities [62,63]. From the results of this project, the knowledge or provision of information alone does not translate directly to the increased likelihood of making a response. The second tier should involve an effort that leads people to formulate and practice actual preparedness behaviors. Although coastal residents may be somewhat unlikely to perform these behaviors on their own, disseminating information and practicing responses in the context of work or community settings both provides the time and space for learning how to respond and also leverages the social learning aspect (i.e., observational learning of others) that is important for both becoming aware of response possibilities and in building personal self-efficacy beliefs [32,33]. Assembling supplies and safety kits for work settings, traveling along evacuation routes, and actually visiting the location of designated hurricane shelters may increase the likelihood of people making similar preparations at home when this becomes necessary. In addition, providing feedback about peoples' responses may build their response efficacy, especially in those cases where preparation behaviors were successful or effective.

The enhancement of hurricane personal self-efficacy also can occur within K-12 school settings. In this regard, the author has used the American Red Cross Master of Disaster (MoD) weather science and safety curriculum to build the knowledge and skills of students who complete the relevant lessons for hurricanes, floods, lightning, and tornadoes [65]. The MoD curriculum offers cutting-edge lessons that are designed to involve parents and family in practical activities like assembling supplies (food, potable water), safety kits, finding the locations of school and home on inundation maps, and evacuation planning. All of these things can build knowledge of possible response options and also increase personal self-efficacy in preparing and evacuating for hurricanes. When work, community, and school preparation efforts are coordinated with hurricane awareness weeks, this may maximize the possibility for practical learning to occur on a regular basis [66].

There are several implications of this project for coastal engineers and planners. First, for engineered structures such as sea walls or flood gates or for evacuation routes like bridges and highways, this project has demonstrated the importance of people knowing about the possible ways that they can respond ahead of a hurricane. For such engineered structures, this means that coastal residents can benefit from knowing 
about both the existence and performance capabilities of structures like sea walls and highways. For example, what height of storm surge can local sea walls withstand before flooding becomes likely? How many motor vehicles can cross a bridge or causeway in a given unit of time under heavy traffic conditions of an evacuation? Publicizing this information can help people to prepare. Knowing what response options are possible contributes to efficacy beliefs that a response (e.g., to use a particular evacuation route) can be made. Similarly, informing both coastal dwellers and emergency managers about areas that are likely to be inundated first from storm surge modeling efforts, is critical in alerting long-time residents and coastal visitors about how they need to respond and when. Third, and following from the discussion above, it is important for people in vulnerable coastal areas to practice hurricane preparation and evacuation ahead of time. Mock storm events (e.g., during hurricane preparedness weeks) can inform people about response options and help them to practice both using and benefitting from the engineered infrastructure.

This study possesses several limitations, one of which was the use of an undergraduate sample that did not dwell on the coast at the time during which the data was gathered. This raises the question about the extent to which the results from the present study may generalize to older adult residents living in areas that could be directly and severely impacted by hurricanes and the accompanying storm surge. Although this is a possibility, the author observed very comparable results between inland undergraduate samples and coastal residents in a study of the ways that hurricane damage perceptions may affect the likelihood of evacuation [17]. In addition, the participants in this study did have experiences with hurricanes: $13.6 \%$ of them had evacuated previously for a hurricane and $15.5 \%$ had sustained hurricane-related property damages. It is an important and necessary first step to use a suitable sample, such as undergraduates with hurricane experiences, for the purposes of developing the HPSES, exploring its psychometric properties, and assessing the extent to which it can be used to model the likelihood of hurricane evacuation. With the accomplishment of these initial efforts, the evaluation of the HPSES with a sample of coastal residents is a logical next step.

Another limitation of the study stemmed from the fact that the author gathered data for this project under conditions in which people were not experiencing any threat of a hurricane, storm surge, or the aftermath of these events. That is, the data in this article represent general and static dispositions to respond that may well differ from the kinds of responses people might make when faced with a particular hurricane situation in real-time. The data and analyses in this project are also cross-sectional with respect to time, rather than sequential. Similarly, the HPSES and other project variables modeled the self-reported likelihood of evacuation and not their actual behavioral responses. Although these are limitations, the present study does provide an informative baseline against which modeling done under more dynamic scenarios could be compared. In addition, evaluating measures like the HPSES in a more general project like this one can help to prepare it for deployment in near- or real-time hurricane situations.

Future research efforts with the HPSES among coastal residents could explore the combined contributions of observing neighbors' hurricane-related responses, information from social and broadcast media, and observing the weather to the levels of hurricane response possibilities and personal self-efficacy that people report. Similarly, to what extent does observing other people take weather-related risks as a hurricane and storm surge approach either inhibit or facilitate similar behaviors in the observer? As prior research has documented, numerous variables influence hurricane preparedness and evacuation [14-30]. The availability of an operational measure of hurricane response possibilities and personal self-efficacy now enables the quantification of these important concepts. 


\section{Acknowledgments}

The author would like to thank Kristin Hunter and Azadeh Fatemi for their assistance in collecting the data for this project.

\section{Author Contributions}

The author designed the Hurricane Personal Self-Efficacy Scale, designed the research to evaluate the instrument, performed all statistical analyses, and wrote the manuscript.

\section{Conflicts of Interest}

The author declares no conflict of interest.

\section{References}

1. Rappaport, E.N. Fatalities in the United States from tropical cyclones. Bull. Am. Meteorol. Soc. 2014, 95, 341-345.

2. Jonkman, S.N.; Maaskant, B.; Boyd, E.; Levitan, M.L. Loss of life caused by the flooding of New Orleans after Hurricane Katrina: Analysis of the relationship between flood characteristics and mortality. Risk Anal. 2009, 29, 676-698.

3. Morss, R.E.; Hayden, M.H. Storm surge and "certain death": Interviews with Texas coastal residents following hurricane Ike. Weather Clim. Soc. 2010, 2, 174-189.

4. Knabb, R.D.; Rhome, J.R.; Brown, D.P. Tropical Cyclone Report: Hurricane Katrina. NOAA National Weather Service, National Hurricane Center. Available online: http://www.nhc.noaa.gov /data/tcr/AL122005_Katrina.pdf (accessed on 20 March 2015).

5. Berg, R. Tropical Cyclone Report: Hurricane Ike. NOAA National Weather Service, National Hurricane Center. Available online: http://www.nhc.noaa.gov/data/tcr/AL092008_Ike.pdf (accessed on 20 March 2015).

6. Blake, E.S.; Kimberlain, T.B.; Berg, R.J.; Cangialosi, J.P.; Beven, J.L. Tropical Cyclone Report: Hurricane Sandy. NOAA National Weather Service, National Hurricane Center. Available online: http://www.nhc.noaa.gov/data/tcr/AL182012_Sandy.pdf (accessed on 20 March 2015).

7. Meyer, R.; Baker, J.; Broad, K.; Czajkowski, J.; Orlove, B. The Dynamics of Hurricane Risk Perception: Real-Time Evidence from the 2012 Atlantic Hurricane Season. Bull. Am. Meteorol. Soc. 2014, 95, 1389-1404.

8. Morrow, B.H.; Lazo, J.K.; Rhome, J.; Feyen, J. Improving storm surge risk communication: Stakeholder perspectives. Bull. Am. Meteorol. Soc. 2015, 96, 35-48.

9. Lazo, J.K.; Morrow, B.H. Survey of coastal U.S. public's perspective on extra tropical-Tropical cyclone storm surge information; National Center for Atmospheric Research: Boulder, CO, USA, 7 January 2013.

10. Saffir, H.S. Hurricane wind and storm surge. Mil. Eng. 1973, 423, 4-5.

11. Simpson, R.H. The hurricane disaster potential scale. Weatherwise 1974, 27, 169-186.

12. National Hurricane Center. Tropical cyclone storm surge probabilities. Available online: http://www.nhc.noaa.gov/surge/psurge.php (accessed March 20 2015). 
13. Horn, D.P. Storm surge warning, mitigation, and adaptation. In Coastal and Marine Hazards, Risks, and Disaster; Ellis, J., Sherman, D.J., Shroder, J., Eds.; Elsevier: Waltham, MA, USA, 2015; pp. 153-180.

14. Blendon, R.J.; Benson, J.M.; Burh, T.; Weldon, K.J.; Herrmann, M.J. High-risk Area Hurricane Survey. Harvard School of Public Health Project on the Public and Biological Security. Available online: http://sphweb.sph.harvard.edu/news/press-releases/files/Hurricane_2008_Total_ Release_Topline.doc (accessed on 20 February 2015).

15. Changnon, S.A.; Pielke, R.A., Jr.; Changnon, D.; Sylves, R.T.; Pulwarty, R. Human factors explain the increased losses from weather and climate extremes. Bull. Am. Meteorol. Soc. 2000, 81, 437-442.

16. Horney, J.; Snider, C.; Malone, S.; Gammons, L.; Ramsey, S. Factors associated with hurricane preparedness: Results of a pre-hurricane assessment. J. Disaster Res. 2008, 3, 1-7.

17. Stewart, A.E. Gulf Coast residents underestimate hurricane destructive potential. Weather Clim. Soc. 2011, 3, 116-127.

18. Baker, E.J. Hurricane evacuation behavior. Int. J. Mass. Emerg. Disasters 1991, 9, 287-310.

19. Dash, N.; Gladwin, H. Evacuation decision making and behavioral responses: Individual and household. Nat. Hazards Rev. 2007, 8, 69-77.

20. Dow, K.; Cutter, S.L. Public orders and personal opinions: Household strategies for hurricane risk assessment. Environ. Hazards 2000, 2, 143-155.

21. Dow, K.; Cutter, S.L. Crying wolf: Repeat responses to hurricane evacuation orders. Coast. Manag. 1998, 26, 237-252.

22. Gladwin, H.; Peacock, W.G. Warning and evacuation: A night for hard houses. In Hurricane Andrew: Ethnicity, Gender and the Sociology of Disasters; Peacock, W.G., Morrow, B.H., Gladwin, H., Eds.; Routledge: New York, NY, USA, 1997; pp. 52-73.

23. Whitehead, J.C.; Edwards, B.; van Willigen, M.; Maiolo, J.R.; Wilson, K.; Smith, K.T. Heading for higher ground: Factors affecting real and hypothetical hurricane behavior. Environ. Hazards 2000, 2, 133-142.

24. Lazo, J.K.; Waldman, D.M.; Morrow, B.H.; Thacher, J. Household evacuation decision making and the benefits of improved hurricane forecasting: Developing a framework for assessment. Weather Forecast. 2010, 25, 207-219.

25. Lindell, M.K.; Lu, J.; Prater, C.S. Household decision making and evacuation response to Hurricane Lili. Nat. Hazards Rev. 2005, 6, 171-179.

26. Stein, R.; Buzcu-Guven, B.; Dueñas-Osorio, L.; Subramanian, D.; Kahle, D. How risk perceptions influence evacuations from hurricanes and compliance with government decisions. Policy Stud. J. 2013, 41, 319-342.

27. Zhang, F.; Morss, R.E.; Sippel, J.A.; Beckman, T.K.; Clements, N.C.; Hampshire, N.L.; Harvey, J.N., Hernandez, J.M.; Morgan, Z.C.; Mosier, R.M.; et al. An in-person survey investigating public perceptions of and responses to Hurricane Rita forecasts along the Texas coast. Weather Forecast. 2007, 22, 1177-1190.

28. Elder, K.; Xirasagar, S.; Miller, N.; Bowen, S.A.; Glover, A.; Piper, C. African Americans' decisions not to evacuate New Orleans before Hurricane Katrina: A qualitative study. Am. J. Public Health 2007, 97, S124-S129. 
29. Kang, J.E.; Lindell, M.K.; Prater, C.S. Hurricane evacuation expectations and actual behavior in hurricane Lili. J. Appl. Soc. Psychol. 2007, 37, 887-903.

30. Ricchetti-Masterson, K.; Horney, J. Social factors as modifiers of Hurricane Irene evacuation behavior in Beaufort County, NC. PLoS Curr. Disasters 2013, 5, doi:10.1371/currents.dis.620b6c2ec 4408c217788bb1c091ef919.

31. Bandura, A. Self-efficacy: Toward a unifying theory of behavioral change. Psychol. Rev. 1977, 84, 191-215.

32. Bandura, A. Social Foundations of Thought and Action: A Social Cognitive Theory; Prentice-Hall: Englewood Cliffs, NJ, USA, 1986; p. 617.

33. Bandura, A. Self-Efficacy: The Exercise of Control. Br. J. Clin. Psychol. 1998, 37, 470.

34. Carberry, A.R.; Lee, H.S.; Ohland, M.W. Measuring engineering design self-efficacy. J. Eng. Educ. 2010, 99, 71-79.

35. Talley, E.; Goodwin, L.; Ruzic, R.; Fisler, A. Marine ecology as a framework for preparing the next generation of scientific leaders. Mar. Ecol. Evol. Perspect. 2011, 32, 268-277.

36. Kulviwat, S.; Bruner, G.C.; Neelankavil, J.P. Self-efficacy as an antecedent of cognition and affect in technology acceptance. J. Consum. Mark. 2014, 31, 190-199.

37. Riggs, I.; Enochs, L. Towards the development of an elementary teacher's science teaching efficacy belief instrument. Sci. Educ. 1990, 74, 625-637.

38. Hyre, A.D.; Benight, C.C.; Tynes, L.L.; Rice, J.; DeSalvo, K.B.; Muntner, P. Psychometric properties of the hurricane coping self-efficacy measure following Hurricane Katrina. J. Nerv. Ment. Dis. 2008, 196, 562-567.

39. Salmun, H.; Molod, A. The use of a statistical model of storm surge as a bias correction for dynamical surge models and its applicability along the U.S. east coast. J. Mar. Sci. Eng. 2015, 3, 73-86.

40. Forbes, C.; Rhome, J.; Mattocks, C.; Taylor, A. Predicting the storm surge threat of Hurricane Sandy with the National Weather Service SLOSH Model. J. Mar. Sci. Eng. 2014, 2, 437-476.

41. Davis, J.R.; Paramygin, V.A.; Vogiatzis, C.; Sheng, Y.P.; Pardalos, P.M.; Figueiredo, R.J. Strengthening the resiliency of a coastal transportation system through integrated simulation of storm surge, inundation, and nonrecurrent congestion in northeast Florida. J. Mar. Sci. Eng. 2014, 2, 287-305.

42. Floyd, D.L.; Prentice-Dunn, S.; Rogers, R.W. A meta-analysis of research on Protection Motivation Theory. J. Appl. Soc. Psychol. 2000, 30, 407-429.

43. Rogers, R.W.; Mewborn, C.R. Fear appeals and attitude change: Effects of a threat's noxiousness, probability of occurrence and efficacy of coping response. J. Personal. Soc. Psychol. 1976, 34, 54-61.

44. Stewart, A.E. Psychological dimensions of adaptation to weather and climate. In Biometeorology for Adaptation to Climate Variability and Change; Ebi, K., Burton, I., McGregor, G., Eds.; Springer: London, UK, 2009; Volume 1, pp. 211-232.

45. Maddux, J.E.; Rogers, R.W. Protection motivation and self-efficacy: A revised theory of fear appeals and attitude change. J. Exp. Soc. Psychol. 1983, 19, 469-479.

46. Rosenstock, I.M. Historical origins of the Health Belief Model. Health Educ. Quart. 1974, 2, 328-335.

47. Ajzen, I. The theory of planned behaviour. Organ. Behav. Hum. Decis.1991, 50, 179-211.

48. Lindell, M.K.; Perry, R.W. Behavioral Foundations of Community Emergency Planning; Hemisphere: Washington, DC, USA, 1992. 
49. Lindell, M.K.; Perry, R.W. Communicating Environmental Risk in Multiethnic Communities; Sage: Thousand Oaks, CA, USA, 2004.

50. Grothmann, T.; Reusswig, F. People at risk for flooding: Why some residents take precautionary action while others do not. Nat. Hazards 2006, 38, 101-120.

51. Milne, S.; Sheeran, P.; Orbell, S. Prediction and intervention in health-related behaviour: A meta-analytic review of Protection Motivation Theory. J. Appl. Soc. Psychol. 2000, 30, 106-143.

52. Stewart, A.E.; Lazo, J.; Morss, R.; Demuth, J. The relationship of weather salience with the perceptions, uses, and values of weather information in a nationwide sample of the United States. Weather Clim. Soc. 2012, 4, 172-179.

53. Simms, J.L.; Kusenbach, M.; Tobin, G.A. Equally unprepared: Assessing the hurricane vulnerability of undergraduate students. Weather Clim. Soc. 2013, 5, 233-243.

54. Stewart, A.E. Minding weather: The measurement of weather salience. Bull. Am. Meteorol. Soc 2010, 90, 1833-1841.

55. Cronbach, L.J. Coefficient alpha and the internal structure of tests. Psychometrika 1951, 16, 297-334.

56. Cortina, J.M. What is Coefficient Alpha? An examination of theory and applications. J. Appl. Psychol. 1993, 78, 98-104.

57. Kromrey, J.D.; Romano, J.; Hibbard, S. ALPHA_CI: A SAS ${ }^{\circledR}$ Macro for Computing Confidence Intervals for Coefficient Alpha. In Proceedings of the SAS Global Forum, Cary, NC, USA, 16-19 March 2008.

58. SAS/STAT User's Guide, Version 9.1; SAS Institute: Cary, NC, USA, 2004.

59. Panter, A.T.; Swygert, K.A.; Dahlstrom, W.G.; Tanaka, J.S. Factor analytic approaches to personality item-level data. J. Personal. Assess. 1997, 68, 561-589.

60. Holgado-Tello, F.P.; Chacón-Moscoso, S.; Barbero-García, I.; Vila-Abad, E. Polychoric vs. Pearson correlations in exploratory and confirmatory factor analysis of ordinal variables. Qual. Quant. 2010, 44, 153-166.

61. Loehlin, J.C. Latent Variable Models: An Introduction to Factor, Path, and Structural Equation Analysis; Lawrence Erlbaum: Mahwah, NJ, USA, 2004.

62. Demuth, J.L.; Morss, R.E.; Morrow, B.H.; Lazo, J.K. Creation and communication of hurricane risk information. Bull. Am. Meteorol. Soc. 2012, 93, 1133-1145.

63. Sherman-Morris, K.; Antonelli, K.B.; Williams, C.C. Measuring the Effectiveness of the Graphical Communication of Hurricane Storm Surge Threat. Weather Clim. Soc. 2015, 7, 69-82.

64. Norris, F.H.; Smith, T.; Kaniasty, K. Revisiting the experience-behavior hypothesis: The effects of Hurricane Hugo on hazard preparedness and other self-protective acts. Basic Appl. Soc. Psychol. 1999, 27, 37-47.

65. Stewart, A.E.; Knox, J.A.; Schneider, P. Piloting and evaluating a workshop to teach Georgia teachers about weather science and safety. J. Geosci. Ed. 2015, submitted.

66. National Weather Service. Weather preparedness events calendar. Available online: http://www.nws.noaa.gov/om/severeweather/severewxcal.shtml (accessed on 27 March 2015).

(C) 2015 by the authors; licensee MDPI, Basel, Switzerland. This article is an open access article distributed under the terms and conditions of the Creative Commons Attribution license (http://creativecommons.org/licenses/by/4.0/). 